СЕЛИВАНОВА Зухра Кадимовна - кандидат социологических наук, доцент Национального исследовательского университета «Московский энергетический институт» (111250, Россия, г. Москва, Красноказарменнаяул., 14; zoi75@bk.ru)

РОДИН Алексей Борисович - директор Гуманитарно-прикладного института Национального исследовательского университета «Московский энергетический институт» (111250, Россия, 2. Москва, Красноказарменная ул., 14; rodinab@треі.ru)

\title{
ГОСУДАРСТВЕННОЕ УПРАВЛЕНИЕ СИСТЕМОЙ ПРОФОРИЕНТАЦИИ СТАРШИХ ПОДРОСТКОВ КАК НАСУЩНАЯ ПРОБЛЕМА СОВРЕМЕННОЙ РОССИИ
}

\begin{abstract}
Аннотация. В статье на основе теоретической и эмпирической научной информации демонстрируется комплекс глубоких социальных и культурных проблем и противоречий в российском обществе, возникающих в связи с отсутствием системы профориентации в стране. Авторы обосновывают острую необходимость возрождения на новой основе системы государственного управления профессиональной ориентацией старших подростков, базирующейся на научных расчетах, прогнозах и регулировании рынка труда, в т.ч. с ориентацией на поступление в конкретные вузы страны.
\end{abstract}

Ключевые слова: старшие подростки, рынок труда, профориентация, государственное управление, школа, высшие учебные заведения

$\Pi$ еред Россией стоят серьезные национально-государственные задачи, связанные с необходимостью модернизации экономики, развитием высокотехнологических отраслей и оборонно-промышленного комплекса.

Одной из важнейших проблем любого социально-экономического проекта является наличие достаточной по количеству и квалификации рабочей силы. Эта задача начинает решаться со школьной скамьи, с комплекса получаемых знаний и ориентации подростков на ту или иную область знаний и набор профессий, выбор вуза, т.е. с ранней профессиональной ориентации подростков 14-17 лет.

В мировой практике государственного управления решения в этой сфере лежат в рамках пространства, ограниченного двумя противоположностями - рыночным и государственным подходами. При этом идеология абсолютно нерегулируемого рынка и идеология абсолютно управляемой экономики - это иллюзии, а на практике происходит сочетание рыночных и государственных механизмов - в каждой стране по-своему в зависимости от модели экономики. Это относится и к регулированию рынка труда.

В директивно-плановой экономике советского периода прогноз и планирование кадрового обеспечения и подготовки кадров исходили из динамики и планов развития отраслей и ведомств, основанных на них разнарядках на подготовку специалистов в профессиональных учебных заведениях среднего специального и высшего образования, текущей и перспективной потребности предприятий. В индустриальную эпоху при наличии достаточно устойчивых трендов развития отраслей этого было достаточно для эффективного решения проблемы распределения кадров в условиях замкнутой национальной экономики. Явные выигрыши, которые имеет экономика с участием механизмов госрегулирования, в начале XXI в. вновь продемонстрировали Китай, Индия, ряд других стран Юго-Восточной Азии уже в условиях частично открытых экономик рыночного типа. 
Альтернативный подход - рыночный. В крайнем варианте рыночно-либерального подхода, реализуемом, например, в США, идеология свободного рынка доминирует и автоматически распространяется на рынок труда, предполагая необходимость его свободы и нерегулируемости. Это означает отсутствие у государственных органов полномочий, функций и задач по организации профориентационной работы на всех уровнях. Но при этом необходимо учитывать, что рыночная система с ее принципом лидерства делает ставку на личную активность граждан и на то, что лучшие кадры соберутся в «центрах силы», т.е. в наиболее развитых странах, и эта стратегия себя оправдывает. А что делать менее развитым странам, в т.ч. современной России, когда такой подход создает условия для отъезда из страны квалифицированных специалистов?

Кроме продолжающихся дискуссий об эффективности той или иной парадигмы управления обществом (и рынком труда), изменилась ситуация в мире в целом. Осуществляется переход к постиндустриальному обществу, к 5-му и 6-му технологическим укладам. Ключевым трендом является резкая активизация развития множества новых направлений техники и технологий, цифровой среды, биоинженерии, медицины, современной энергетики и других высокотехнологических отраслей, что вскоре поменяет не только облик человечества - его возможности, систему услуг, коммуникации, но и социальную структуру общества, характеристики труда. Уже в недалекой перспективе вполне очевидна проблема вытеснения человека роботами из целого ряда отраслей и традиционных профессий. Новым серьезным фактором профессионального выбора в современную эпоху стало постоянное ускорение динамики перечня востребованных профессий. Так, А.Г. Асмолов пишет: «Десяти самых востребованных профессий 2010 г. шесть лет тому назад еще не существовало. «... По прогнозам Министерства труда США, современные старшеклассники к своим 38 годам сменят от 10 до 14 мест работы. ‘..> Нам всем надо понимать, что нынешние студенты будут работать по профессиям, которых еще нет, использовать технологии, которые еще не родились, и решать задачи, о которых мы не знаем» [Асмолов 2010: 78]. И это так. Другой важной особенностью современности стала открытость рынков труда различных стран, что позволяет молодежи искать применения своих сил не только в своей стране, но и за рубежом. Сторонники радикального либерально-рыночного устройства общества этими аргументами продолжают оправдывать ненужность государственных систем управления трудовыми ресурсами и профориентации, а сторонники государственного регулирования уверены, что такая система в современных условиях необходима все острее, причем на новом качественном уровне организации и информации, по крайней мере потому, что ситуация в национальных экономиках менее развитых стран осложняется, в т.ч. и в России. Более того, многие вузы страны уже прямо ориентируются на подготовку специалистов из числа российской молодежи для других стран. При этом важно отметить, что значительную финансовую нагрузку по подготовке специалистов продолжает нести государство и при отсутствии государственной политики в сфере труда это ведет к необоснованному распылению бюджетных средств из-за выезда за границу специалистов, получивших образование за государственный счет [Горшков, Шереги 2010: 220-221].

Пока же в современной российской экономике подростку чрезвычайно сложно найти себя и сделать перспективный профессиональный выбор как вследствие динамических изменений в сфере производства, так и вследствие отсутствия государственных стратегий и прогнозов. В постсоветской России в соответствии с идеологией и системой рыночной организации экономики отсутствует удаленный стратегический прогноз и долгосрочная государ- 
ственная политика в сферах производства, пространственного размещения производительных сил (региональное планирование), профессионального образования, в информационной сфере. Хотя при этом, как отмечают специалисты по проблеме трудовых ресурсов из Новосибирска, начиная с 1990-х гг. проблема профориентации «обсуждалась как в научной среде, так и на различных правительственных и общественных форумах. Однако до сих пор не выработано адекватного решения этой проблемы. При этом периодически принимались меры, направленные на регулирование этого дисбаланс, как на федеральном, так и на региональном уровне, но желаемый результат не был достигнут» [Харченко, Арсентьева 2019]. Существующий дисбаланс и отсутствие государственной политики и прогнозов в сфере управления трудовыми ресурсами, а также отсутствие системы государственной профориентации ведет к двум эффектам - гигантскому перепроизводству специалистов по ряду «модных», но не востребованных профессий ${ }^{1}$ (соответственно, к нерациональным тратам ресурсов и сил людей, общества, государства) и одновременно к дефициту специалистов востребованных профессий (особенно инженерных и рабочих кадров). Другое следствие - снижение уровня профессионализма как в сфере непопулярных, но востребованных профессий (вследствие отсутствия конкуренции, случайного подбора кадров, ремесленного «обучения» на местах и самообучения), так и в высокопрестижных сферах, которые во многом заполняются непрофессионалами под давлением рынка выпускников. При сохранении нынешних отношений в этой сфере положение будет лишь усугубляться.

На данный момент в России нет государственной системы управления кадровой политикой, регулирования рынка труда, системы профориентации. Ситуация в организации системы профориентации в России определяется несколькими факторами:

- отсутствием в рыночной экономике установок на создание государственной системы профориентации и управления рынком труда, ориентира на свободный рынок труда, отсутствием в России государственной системы профориентации;

- социально-исторически обоснованным и логичным (особенно в условиях отсутствия государственной системы профориентации) стремлением школы как общественного института и большинства педагогов инициативно компенсировать дефицит информации, дать хоть какие-то ориентиры в выборе профессий своим ученикам, сориентировать их для поступления в вузы;

- внесистемной профориентацией силами семьи, друзей, СМИ, Интернета и в целом давлением деформированного и дезориентированного в сфере профессиональной ориентации общественного мнения.

Результатом этого положения в стране является хаотичность факторов при выборе профессии и огромный процент ошибочных выборов. Так, в исследовании 2017-2018 гг. среди студентов Московского энергетического института (НИУ «МЭИ») в качестве решающих факторов и мотивов при поступлении в вуз и выборе НИУ «МЭИ» студенты отметили: престиж вуза (42\% выборов); влияние друзей, знакомых, родственников (45\%); привлекательность профиля вуза (энергетика) - 30\%. Кроме того, возрастает влияние мотива «легко было поступить (невысокий конкурс)» [Селиванова, Кузьминов 2020]. По результатам других исследований, лишь пятая часть студентов уверены в выборе профессии, половина сомневаются, а пятая часть студентов утверждают, что выбрали про-

\footnotetext{
1 Это демонстрирует ситуация с перепроизводством юристов, менеджеров, экономистов: на одно реальное место в такой профессии годы подряд выпускались и выпускаются сотни специалистов.
} 
фессию случайно [Харченко, Арсентьева 2019]. Поэтому в итоге более половины выпускников вузов работают не по специальности, а по некоторым профессиям - до 90\% [Курбатова, Рубцова, Калачев 2019]. Получается, что значительное большинство молодых людей ошиблись с выбором профессии.

Конечно, каждый молодой человек осуществляет выбор своего жизненного пути индивидуально. Но общество и государство не имеют права забывать, что этот индивидуальный выбор социален, общественно обусловлен, должен быть социально подготовлен во избежание жизненного фиаско молодых людей. Поэтому в основе профориентации должны лежать долгосрочные интересы государства, общества, обеспечивая каждому гражданину осознание перспективы выбора профессии и полноценной реализации конституционного права на труд. В настоящее же время в отсутствие механизма профориентации школьники, учащиеся училищ и колледжей чрезвычайно плохо осведомлены о будущей работе, ее требованиях, ее социальных перспективах, откуда вытекает хаотичность предпочтений в выборе профессий, отсутствие ее связи с объективными потребностями общества [Селиванова 2017].

Фактической оценкой результатов 20-летних реформ системы высшего профессионального образования еще весной 2011 г. стало выступление вицепремьера РФ С. Иванова на заседании коллегии Минобрнауки, где он прямо заявил о переизбытке общего числа вузов в России, несоответствии качества образования в некоторых из них «современным стандартам», сильном перекосе в выпуске тех или иных специалистов в сторону экономистов и управленцев и одновременном росте дефицита кадров по многим специальностям. Ситуация за прошедшие 10 лет никак не изменилась.

Одной из важных причин, безусловно, является характер информации и информационных ресурсов, находящихся в распоряжении подростка и его родителей на момент выбора профессии. На сегодня весь набор социальных и ценностных ориентиров и информационных ресурсов, находящихся в распоряжении подростка и воздействующих на него при выборе будущей профессии, имеет очень разнохарактерный состав. В него входят профориентационная работа в общеобразовательной школе и в различных школах по искусству, в секциях и кружках; влияние родителей; влияние сверстников; влияние СМИ, Интернета и других информационных и коммуникационных ресурсов; информация профессиональных учебных заведений среднего и высшего образования России и зарубежья; информация о вакансиях от работодателей и различных агентств по поиску работы и найму в стране и в мире. Подавляющее большинство информационных ресурсов ориентированы на текущие потребности рынка труда, причем характер и сила воздействия этих информационных ресурсов на подростков никак не исследуются и не учитываются в профориентационной работе.

Так, в средних школах продолжает инициативно вестись профориентационная работа, совершенствуются ее теория, практика, методики и различные аспекты. Этой проблеме посвящены сотни работ по педагогике, психологии, организации в разных аспектах и по разным профессиям. Однако «подавляющее большинство общеобразовательных учреждений проводит профориентацию преимущественно собственными силами» [Шафранов-Куцев, Ефимова, Семенов 2018: 58]. Это обусловливает низкую результативность школьной профориентации и делает наиболее влиятельным внешкольное окружение (родители, друзья, СМИ, собственные наблюдения за жизнью и т.д.) [Харченко, Арсентьева 2019]. В итоге оказывается, что «основная тяжесть профориентационной работы на сегодняшний день легла на плечи семьи... Фактически семья оказалась один на один с решением проблем профессионального самоопреде- 
ления ребенка», а эффективность профориентационной работы других агентов социализации и воспитания, включая школу, оценивается как крайне низкая [Немова, Медведева 2019: 173], несмотря на то что редкие опросы самих подростков о качестве профориентационной работы дают в среднем положительные оценки [Гуляева 2018]. При этом понятно, что родители чаще всего исходят из интересов и возможностей ребенка в сочетании с перспективами знакомых им на личном опыте видов профессий и информации СМИ [Карцева 2019]. Но ни родители, ни педагоги не являются специалистами по всем профессиям, экспертами по рынку труда, не видят и не понимают (и не должны понимать) стратегию развития страны, отраслей, регионов, трендов рынков труда и профессий. В итоге основными факторами выбора вуза и профессии являются собственные интересы, советы родителей и друзей, и можно полностью согласиться с тем, что «профессиональный выбор молодежи во многом является неосознанным» [Горина, Морозова, Шикина 2013: 121] и никак не обоснованным - ни научными расчетами, ни объективными потребностями рынка, ни перспективами тех или иных профессий.

Профориентация должна вновь стать делом государства, результатом прогнозирования и планирования, учета стратегии экономики в профориентационной деятельности [Половинко, Диннер 2017: 28]. В сочетании факторов выбора профессии «хочу, могу, рынок труда» в России необходимо промежуточное звено - государственный прогноз развития экономики и социальной сферы и профориентация подростков на рынке труда. Остро необходимо возродить государственную систему профориентации и ее комплексное научное сопровождение, в т.ч. раннюю профориентацию старших подростков. Формирование комплекса информационных ресурсов профориентации должно носить системный и научно обоснованный характер, входить в комплекс научных исследований и в систему государственного управления образованием. Примеры профориентационных прогнозов есть в некоторых развитых странах с социально ориентированной экономикой.

В организации профориентационной работы необходима целостная концепция, программа, скоординированные усилия многих социальных институтов от отраслевого и регионального прогноза и планирования рынка труда до профориентационной работы на уровне школы. Необходимо вновь вспомнить, что профориентация личности - это специальная работа, которой должны заниматься специально подготовленные люди, в т.Ч. профориентологи, которые ориентируются в динамике рынка труда и одновременно способны провести психологический анализ личности, анализ интеллекта, желаний и склонностей, ценностных ориентаций, личностных качеств и способностей подростка и выдать обоснованный список рекомендованных профессий ${ }^{1}$. Может использоваться сочетание разных организационных форм - от создания федеральной площадки [Шафранов-Куцев, Ефимова, Семенов 2018: 61] и воссоздания центров профориентации, закрытых в 2003 г. [Кривцова 2010: 87], до разработки новых форм. Главное, это должна быть государственная работа, комплексно организованная на постоянной основе. Научная теория, отечественная и мировая позитивная и негативная практика показывают, что без создания и осуществления на современном уровне научно обоснованной государственной политики и управленческой практики в системе подготовки кадров, профессиональной ориентации никакие модернизационные стратегические проекты не осуществимы. Большая роль в создании такой системы должна быть отведена науке - статистике,

1 Профориентация школьников. Доступ: http://www.profguide.ru/article/proforientation in_school.html (проверено 18.01.2021). 
социологии, педагогике, психологии. Полученные ранее и современные научные результаты могут стать серьезной основой для выработки государственной политики в этой сфере, давая многосторонний анализ динамики социального запроса на профессии и мотивов профессиональных предпочтений, позволяя выйти на прогнозирование последствий профессионального выбора.

\section{Список литературы}

Асмолов А.Г. 2010. Образование должно стать институтом социального развития общества: материалы круглого стола «Опыт социализации подростков и молодежи: политика бизнеса, государства и гражданского общества». Образовательная политика. № 9-10(47-48). С. 78-91.

Горина Е.Е., Морозова А.В., Шикина Е.А. 2013. Профориентация в решении проблем диспропорций в сфере занятости и обеспечения рынка труда инженерными кадрами. - Известия Юго-Западного государственного университета. № 6(51). Ч. 1. С. 121-125.

Горшков М.К., Шереги Ф.Э. 2010. Молодежь России: социологический порmрет. М.: ЦСПиМ. 592 с.

Гуляева Л.В. 2018. Влияние профориентационных мероприятий как фактора профессионального самоопределения на конкурентоспособность старшеклассников. -Образование: молодежь, конкурентоспособность: сборник докладов международной научно-практической конференции. Тюмень, 21-22 сентября 2018 г. Тюмень: Изд-во ТюмГУ. С. 127-131.

Карцева Л.В. 2019. Профориентационные установки родителей старшеклассников и их влияние на профессиональное самоопределение учащихся школы. - Вестник Нижегородского университета им. Н.И. Лобачевского. Сер. Социальные науки. № 2(54). С. 68-83.

Кривцова С. 2010. Шаг вперед, два шага назад: материалы круглого стола «Опыт социализации подростков и молодежи: политика бизнеса, государства и гражданского общества». - Образовательная политика. № 9-10(47-48). C. 78-91.

Курбатова А.С, Рубцова Н.В., Калачев Е.Ю. 2019. Проблемы и перспективы профориентационной работы в современных условиях. - Азимут научных исследований: педагогика и психология. Т. 8. № 4(29). С. 119-122.

Немова О.А., Медведева Т.Ю. 2019. Свобода профессионального выбора и профориентация: ренессанс дикого капитализма или шаг вперед? - Азимут научных исследований: педагогика и психология. Т. 8. № 2(27). С. 172-175.

Половинко В.С., Диннер И.В. 2017. Влияние профориентации на миграцию и перспективы рынка труда. - Вестник Тюменского государственного университета. Социально-экономические и правовые исследования. Т. 3. № 3. С. 19-32.

Селиванова 3.К. 2017. О жизненных целях и профессиональных предпочтениях старших подростков. - Социс. Социологические исследования. № 5. С. 51-56.

Селиванова 3.К., Кузьминов М.Ю. 2020. МЭИ глазами студентов: социологический аспект. - Современный мир: стратегии развития, технологии и образы будущего»: материалы международной научно-практической конференции «V Арефьевские чтения». Москва, 24-25 октября 2019 г. М.: Изд-во МЭИ. C. 257-261.

Харченко И.И., Арсентьева Н.М. 2019. Парадоксы профессиональной ориентации молодежи: что в приоритете - интересы и самореализация или потребности экономики. - Социодинамика. № 12. С. 86-102.

Шафранов-Куцев Г.Ф., Ефимова Г.З., Семенов М.Ю. 2018. Профориентационные практики в условиях глобализации: социологический анализ. - Образование и наука. Т. 20. № 8. С. 46-65. 
SELIVANOVA Zuhra Kadimovna, Cand.Sci. (Soc.), Associate Professor of the National Research University «Moscow Power Engineering Institute» (14 Krasnokazarmennaya St, Moscow, Russia, 111250; zoi75@bk.ru)

RODIN Aleksei Borisovich, Director of the Humanitarian-applied Institute, National Research University «Moscow Power Engineering Institute» (14 Krasnokazarmennaya St, Moscow, Russia, 111250; rodinab@mpei.ru)

\section{STATE MANAGEMENT OF THE CAREER GUIDANCE SYSTEM FOR SENIOR TEENAGERS AS AN URGENT PROBLEM IN MODERN RUSSIA}

Abstract. On the base of theoretical and empirical scientific information, the authors demonstrate a complex of deep social and cultural problems and contradictions in Russian society that arise due to the lack of a career guidance system in the country. They justify the urgent need to revive on a new basis the system of state management of professional orientation of senior teenagers, based on scientific calculations, forecasts and regulation of the labor market, including an orientation towards admission to specific universities in the country.

Keywords: senior teenagers, labor market, career guidance, public administration, school, higher education institutions

АГИШЕВ Руслан Ряфатевич - кандидат исторических наук, ведущий научный сотрудник отдела мониторинга правовых процессов Научного иентра социально-экономического мониторинга Республики Мордовия (430005, Россия, Республика Мордовия, г. Саранск, ул. Богдана Хмельницкого, 39A; agishev2019@gmail.com)

МАНАЕВА Ирина Владимировна - научный сотрудник отдела мониторинга правовых процессов Научного иентра социально-экономического мониторинга Республики Мордовия (430005, Россия, Республика Мордовия, г. Саранск, ул. Богдана Хмельницкого, 39A; manaeva.i.v@таil.ru)

\section{КОРРУПЦИЯ И МИЛЛЕНИАЛЫ: РЕГИОНАЛЬНЫЕ ПРАКТИКИ ПОВЕДЕНИЯ}

\footnotetext{
Аннотация. Статья посвящена специфике коррупционных практик миллениалов в реалиях дотационного региона с негативной динамикой социально-экономических отношений. Актуальность поднимаемых вопросов обусловлена и неоднородностью коррупции как социального явления, и быстрой трансформацией коррупционных явлений, и запаздыванием научного осмысления феномена молодежной коррупции. В статье идет речь о выявлении преобладающих черт регионального коррупционного поведения такой возрастной когорты, как миллениалы, которые обладают целым рядом особых психовозрастных качеств (клиповое сознание, технологическая продвинутость, амбициозность, ускоренный темп жизни, отсутствие рефлексии, стартовая обеспеченность, ценностная виртуальность). Базой для анализа коррупционных практик выступила серия социологических исследований, проведенных ГКУ РМ «Научный центр социально-экономического мониторинга» в Республике Мордовия в 2007-2019 гг. Выявлены широкое распространение коррупционного опыта, достаточно высокий уровень регулярной коррупции, совершение преобладающего числа коррупционных сделок в строго определенных сферах, удорожание коррупционного поведения, противоречивая оценка действий взяткодателя и взяткополучателя и т.д. Авторы подчеркивают существование системы двойных стандартов, когда собственное коррупционное поведение не имеет негативную окраску и считается вынужденным, а чужое оценивается в качестве общественно опасного деяния, и формулируют предположение, что коррупционное поведение миллениалов приобретает функциональный и адаптационный характер. Ключевые слова: коррупция, взятка, коррупционное поведение, сферы коррупционного взаимодействия, поколение миллениалов, коррупционная активность.
} 